\title{
Educational System for the Holy Quran and Its Sciences for Blind and Handicapped People Based on Google Speech API*
}

\author{
Samir A. Elsagheer Mohamed1,2, Allam Shehata Hassanin'3, Mohamed Tahar Ben Othman ${ }^{4}$ \\ ${ }^{1}$ Computer Engineering Department, College of Computer, Qassim University, Qassim, KSA \\ ${ }^{2}$ Faculty of Engineering, Aswan University, Aswan, Egypt \\ ${ }^{3}$ Electronic Research Institute, Giza, Egypt \\ ${ }^{4}$ Computer Science Department, College of Computer, Qassim University, Qassim, KSA \\ Email: samhmd@qu.edu.sa, samirahmed@yahoo.com, almohager093@yahoo.com, \\ maathaman@qu.edu.sa, mtothman@gmail.com
}

Received 12 October 2013; revised 12 November 2013; accepted 19 November 2013

Copyright (C) 2014 by authors and Scientific Research Publishing Inc.

This work is licensed under the Creative Commons Attribution International License (CC BY).

http://creativecommons.org/licenses/by/4.0/

(c) (i) Open Access

\section{Abstract}

There is a great need to provide educational environments for blind and handicapped people. There are many Islamic websites and applications dedicated to the educational services for the Holy Quran and Its Sciences (Quran Recitations, the interpretations, etc.) on the Internet. Unfortunately, blind and handicapped people could not use these services. These people cannot use the keyboard and the mouse. In addition, the ability to read and write is essential to benefit from these services. In this paper, we present an educational environment that allows these people to take full advantage of the scientific materials. This is done through the interaction with the system using voice commands by speaking directly without the need to write or to use the mouse. Google Speech API is used for the universal speech recognition after a preprocessing and post processing phases to improve the accuracy. For blind people, responses of these commands will be played back through the audio device instead of displaying the text to the screen. The text will be displayed on the screen to help other people make use of the system.

\section{Keywords}

Blind; Illiterate and Manual-Disabled People; Quran Sciences; Speech Recognition; Learning Systems

\footnotetext{
*This work is sponsored by Noor ITC (www.nooritc.org), project no NRC1-29.
} 


\section{Introduction}

For Muslims, the best science ever are learning Quran (memorization, recitation, narration, interpretation, etc.) with the help of highly qualified Quran's reciters (those learned recitation in a linked sequence of persons attached to the prophet Mohamed peace be upon him). Scientists wrote many books on different Quran's recitations, narration, interpretations, and the scientific Mutoons (rules and regulations for the correct recitation and reading of the Holy Quran). As example, Imam Ibn Aljazari has collected in his book "publishing in ten recitations" fifty-eight books which are about the recitations. Allah has raised people of Quran who learned and taught it, He Almighty said (translation of the meanings from the Quran to English):

"Indeed, those who recite the Book of Allah and establish prayer and spend [in His cause] out of what We have provided them, secretly and publicly, [can] expect a profit that will never perish. That He may give them in full their rewards and increase for them of His bounty. Indeed, He is Forgiving and Appreciative", Surat Faater -Orginator (35), Verses 29-30.

Also the Prophet PBUH, in Al-saheehayn (the two authentic Books) from Osman Ibn Affan may Allah be pleased with him the Messenger of Allah PBUH said: "The best among you is who learned and taught the Quran".

From this logic, great efforts in recent years were conducted to adapt information technology and computer applications, particularly the use of websites and Web pages in religious sciences and provided to all categories of Muslims worldwide in all forms, whether printed, audio or video to benefit all classes of Muslim society. That prompted those interested in servicing the Holy Quran to collect and constructs several libraries of text, audio and video materials for the Holy Quran and Its Sciences. These libraries are now available on the Web sites and Web pages.

Unfortunately, there are several categories of people who cannot make use or access these libraries. These categories include our valued brothers with blindness, handicapped people with manual disabilities, illiterate people and children who not yet able to read. These people may be eager to learn the Holy Quran.

In this Paper, we present a system that we have developed that allows these categories of people in addition to the normal people to take full advantage of the available scientific materials, such as: the Quran Recitations, the interpretations, the scientific materials (Mutoon), etc. This is done through the interaction with the system using voice commands by speaking directly without the need to write or to use the mouse or the keyboard. Results of these commands will be played back through the audio device instead of displaying the text to the screen. The text is displayed on the screen as well to help normal people make use of the system.

Just to clarify the idea, the user can orally pronounce this command: Read Surat Al-Emran from verse number 20 to 30, Repeat three times using Khalaf An Hamza recitation. The system recognizes these commands. Then it fetches the corresponding prerecorded audio material from the remote server. It then plays back the required set of verses to the user.

The system includes very accurate speech recognition mechanism. Thus, people can dictate the commands by voice and the system can recognize them accurately and execute them. This feature allows the targeted categories of people to make use of the system exactly like the normal people without having to use the mouse, the keyboard and without having to read from the screen.

We have also constructed a huge digital library containing all the required audio materials to cover most of the Quran Sciences. This allows these people to easily access the contents of this library through the developed system and the web application.

The rest of this Paper is organized as follows. In Section 2, we present the relate works. The digital library that we have constructed for the Holy Quran and Its Sciences is described in Section 3. We present the components of the system in Section 4. In Section 5, we present the application that can be used by the targeted categories of people to learn from that digital library. The conclusions and future directions are given in Section 6 .

\section{Related Works}

Several researchers were conducted and electronic devices and software were built to help blind people to read literature and written communication. The main and worldwide known system is the Braille system. Braille is a system of touch reading and writing for blind persons in which raised dots represent the letters of the alphabet. Braille also contains equivalents for punctuation marks and provides symbols to show letter groupings. Muslim people used also this system for Quran to help blind people reading it. Some proposed an eBraille like in [1] 
which is an electronic Braille panel for reciting Al-Quran. In the other direction [2] built a Quranic Braille System translating Quranic verses to Braille symbols, by using Visual basic program. This system helps blind people to read Quran with the special vibration related to Quran. [3] proposed a portable electronic Braille which can be connected to a computer and helps in teaching the visually impaired to learn and read Al-Quran. Some other papers were suing speech recognition to help users to read the Quran as it should be. Among these the paper [4]-[6] introduces a multimedia type system with pre-recorded Holy Qur'an recitations, recitation teaching text materials and teaching animations that helps students to learn how to recite the holy Qur'an and to correct their mistakes in formal Arabic pronunciation. A new pedagogical model to help primary school teachers teach Quranic recitation is introduced in [7]. The proposed model would help to increase learners' skills, attitude, motivation, grade, and knowledge while learning how to recite the Quran. Although these contributions and others [7]-[19] brought a considerable help to Muslims who would like to learn Quran, most of them did not take into account several categories of Muslims which desperately need them. It is these groups visually impaired and disabled manually, illiterate, and children who cannot read.

\section{Digital Library for the Holy Quran Sciences}

The Holy Quran [20] [21] is the book literally meaning "the recitation” and is the main religious text of Islam. It is the verbatim words of God (Allah). Quran was revealed through angel Gabriel from Almighty God to the proph- et Muhammad (may peace be upon Him).

There are several sciences of the Holy Quran. They include, but not limited to, recitations, interpretations, scientific Mutoon, and memorization.

There are ten famous Quran recitations (a.k.a reading, or Qira'ah). In each recitation, there is two famous narrations (Rewah). The most popular reading is that of Hafs on the authority of asim. Similarly, each melodic passage centers on a single tone level, but the melodic contour and melodic passages are largely shaped by the reading rules, creating passages of different lengths whose temporal expansion is defined through caesuras [22].

These ten recitations consists of 7 Mutawatir (a transmission which has independent chains of authorities so wide as to rule out the possibility of any error and on which there is consensus) and 3 Mashhur (these are slightly less wide in their transmission, but still so wide as to make error highly unlikely) ways of reading [22].

The audio library that we have constructed consists of many audio files grouped and structured in a logical format, where each file is encoded with platform independent MP3 encodings. These recordings are divided as follows:

1) Audio recordings of the Quran's ten recitations and two narrations in each recitation;

2) Audio recordings of the five most famous and prestigious interpretations of the Quran;

3) Audio recordings of scientific Mutoon (متون) related to the readings science and Tajweed and the learning and memorization helpers of Quran.

The following is a detailed explanation of what has been done with these recordings and how they are processed:

\subsection{Audio Recordings of the Quran Ten Recitations and Their Narrations}

We have prepared the audio materials for the ten recitations of Quran and the twenty narrations. Each verse in every narration is stored in a separate audio file with high quality recording. Additionally, further lossy compressed versions of each file are constructed to suite those having different constraints in the Internet connection speed. The prepared audio recordings of the Quran contain the whole verses of the Quran for the following twenty narrations:

1) Imam Qaaloon from Imam Nafi

2) Imam Warsh from Imam Nafi

3) Imam Albzi from Imam Ibn Kathir

4) Imam Konbul from Imam Ibn Kathir

5) Imam Aldoory from Imam Abi Amr Albusary

6) Imam Alsossi from Imam Abi Amr Albusary

7) Imam Hisham from Imam Ibn Amer

8) Imam Ibn Zakwan from Imam Ibn Amer

9) Imam Shoba from Imam Asim 
10) Imam Hafs from Imam Asim

11) Imam Khalaf from Imam Hamza

12) Imam Khallad from Imam Hamza

13) Imam Abu Alhareth from Imam Alkisai

14) Imam Aldury from Imam Alkisai

15) Imam Ibn Werdan from Imam Abu Ja’far

16) Imam Ibn Jammaz from Imam Abu Ja'far

17) Imam Rwis from Imam Jacob

18) Imam Rooh from Imam Jacob

19) Imam Ishaq from Imam Khalaf

20) Imam Idris from Imam Khalaf

Note that the Quran's audio materials are downloaded from the NOON website (nquran.com) after getting a written approval from the site administrations. These audio files, then, were processed, sorted and saved into our digital library. This was done for each of the above listed narrations with a separate audio file for each verse of the Quran recited by the voice of famous sheikhs.

It is well known, that the high quality of the audio files takes a huge size and therefore takes a long time to download from the site when it is needed. For users having slow Internet connection, this process takes a long time and makes big unsatisfactory breaks between a verse and the next one. Therefore, we have re-encoded and compressed each audio file separately so that for each verse in each narrations, four different audio files are constructed from the original one as follows:

1) An audio file for each verse in the highest quality. It is suitable for those with a very high speed Internet connection, where the coding rate is 128 kilobits per second.

2) An audio file for each verse in high quality. It is suitable for anyone who has a high-speed connection to the Internet, where the coding rate is 64 kilobits per second.

3) An audio file for each verse in average quality. It is suitable for anyone who has a medium connection speed to the Internet, where the coding rate is 32 kilobits per second.

4) An audio file for each verse in low-quality. It is suitable for anyone who has a slow Internet connection speed, where the coding rate is 8 kilobits per second.

\subsection{Sound Recordings of the Prestigious Interpretations (Tafseer) of the Quran}

This Section of the digital library is reserved for the Quran interpretation. We have added two of the most famous interpretations, namely: Altafseer Almuyassar and Tafseer Alsaadi.

Altafseer Almuyassar is prepared by a group of elite scientists and approved by the King Fahd Complex for Printing the Holy Quran in Saudi Arabia. Unfortunately, there is no audio recording for the text narrated by any one. Thus, we had to do the recordings and the revisions ourselves. Thus, Eng. Allam Shehata who has a very good presentation skills and his voice has a solid tones, and he knows the recitations rules is employed to read from the text in the book and read each verse and record it in a separate file. After that, the files are organized and indexed using the predefined logical structure of the digital library we are creating. These files are then added to the library. Another team is listening to the recorded audio files for each verse and match it with the text. In the case of any problem including the voice tones, the verse is re-recorded and added back into the digital library.

In the second interpretation, Tafseer AlSaadi, for each group of related verses, an audio file with high quality recording is constructed. The contents of all the audio files are indexed and added to the digital library.

\subsection{Audio Recordings of Scientific Mutoon (متون) on Tajweed and Recitation Sciences}

We have prepared the audio materials of the most known Mutoon (scientific learning materials) related to Quran. In each one of these Mutoon, a number of audio files are generated containing the narrated group of Bayt (Sections/Chapters). Each file contains subsection of the considered Matten (singular form of Mutoon).

The collection and processing of scientific Mutoon texts is done with a high quality recorded voice. These Mutoon are invented by the most known sheikhs and scholars in the Muslim world who are specialist. Below is the description of the sound recordings that have processed: 
1) Matten Harz AlAmani Wa Wajh Attahani in seven readings (AlShatebya). This Matten is authored by the Imam of the investigators, Al-Qasim Ibn Firah Ibn Khalaf Ibn Ahmed Shaatibi Alayni AlAndalusi died in 590 $\mathrm{AH}$.

2) Matten AlDurra Almadhiyah in the three recitations (Al-Durra). This Matten was authored by Imam AlHafiz Sheikh of the reciters and the narrators Imam Muhammad Ibn Muhammad Ibn Mohammed Ibn Ali Ibn Yousef Ibn Aljazari, known as Ibn Aljazari who died in 833 AH.

3) Matten Almanzouma Aljazaria. This Matten was authored by Ibn Aljazari who died in $833 \mathrm{AH}$.

4) Matten the masterpiece of children (Tuhfat Alatfal). This Matten was authored by Sheikh Suleiman Ibn Hussein Ibn Muhammad Aljmzori, who died in $1204 \mathrm{AH}$.

5) There are many other Mutoon which are been indexed and included into the digital library.

\subsection{Text Based Materials in the Digital Library}

Although the main goal of the project is to target the people who cannot read text or use the keyboard and the mouse, we considered the other categories of people who can read. This includes people having manual disabilities and the normal people. Thus, it is essential to include in our digital library the text versions of all the materials: Quran text, Tafseer Text and Mutoon Text. Thus, we have prepared the following:

1) Two authentic Quran Mushafs: It is known that the electronic versions of Mushaf may contains errors, thus, to avoid this, we have decided to use only the images (photocopies) of the authentic Mushafs. The prepared Mushafs are: Almadina version printed and produced in the King Fahd Quranic Complex and Altajweed Mushaf (having the text colored based on the rule of recitations). Many other Mushafs are prepared, but not included in the system until recognizing their authenticity.

2) The text files for each of the five most known interpretations (Tafeer). In each Tafseer, an indexed file for each verse is created. The file contains the Verse's text and the corresponding interpretation text. The prepared interpretations are: Ibn-Katheer, Alsaadi, Almoyassar, Al-Jallalin, Al-Tabari, and Al-Qurtobi.

3) The text materials of the most known Mutoon related to Quran (see the previous Sections for the names of the considered Mutoon). For each one of the considered Mutoon, a number of indexed text files are generated containing to the Subsection or Section.

\section{Components of the Developed System}

In this Section, we present the components of the developed system.

\subsection{Speech Recognition Engine}

We have invented a speech recognition [10]-[13] [19] engine for the Arabic spoken phrases. It is based on the recently developed Google Speech API. It is speaker independent that means that any user can use it and it will recognize the spoken phrase accurately regardless of the specific personal feature of each user voice, without the need for training or retraining. It supports the Arabic language with several Arabic accents (Egypt, Saudi Arabia, Algeria, etc.) The accuracy is very high and it can reach up to $100 \%$ in the case when several simple rules are followed (speaking clearly and loudly, and disabling the recording enhancements of the microphone, and adjusting the recording level to $70 \%$ without boosting).

The mechanism is as follows (See Figure 1 for a simplified block diagram):

1) The user speaks a phrase, then we record his/her voice in a file.

2) Several sound processing are carried out (noise removal, filtering, silence removal, etc.).

3) The file encoding is then converted to "flac" encoding with the required sampling rate of 16,000 and mono channel.

4) The resultant file is posted to "google" servers using the HTTP protocol with some parameters that we set for them. "Lang" parameter can be any of the supported languages: ar-Sa (Saudi Arabia), ar-Eg (Egyptian), etc. as in the following link.

http://www.google.com/speech-api/v1/recognize?xjerr=1\&lang=ar-Eg\&client=chromium

5) Google Speech API servers convert the speech into text and return the text back to our application using JSON format. 


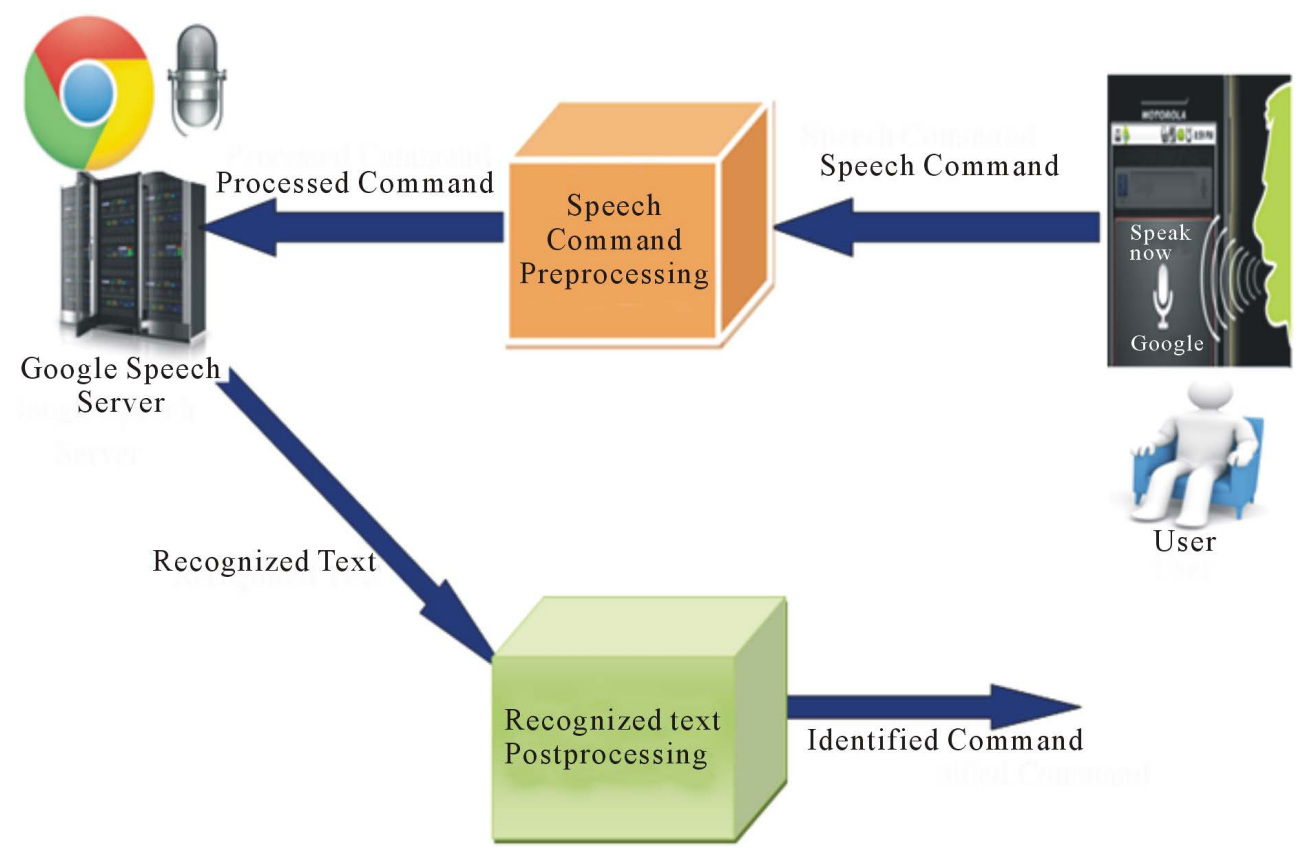

Figure 1. Block diagram of the speech recognition engine.

6) The accuracy of the recognized text by google is very bad in many cases. For Arabic it is around $50 \%$. Thus, we have added several post processing phases on the text to increase the accuracy.

7) The post processing phase consists of using the approximate string searching and normalization within the expected spoken set of phrases.

8) We have carried several experimentations of the post processing phase with 14 different approximate string matching algorithms, which are as follows:
a) SmithWaterman
b) SmithWatermanGotoh
c) SmithWatermanGotohWindowedAffine
d) QGramsDistance

e) NeedlemanWunch

f) MongeElkan

g) Levenstein

h) JaroWinkler

i) JaccardSimilarity

j) EuclideanDistance

k) DiceSimilarity

l) CosineSimilarity

m) BlockDistance

n) ChapmanLengthDeviation

9) After applying each algorithm to recognize many texts recognized by "google speech API" to the names of the names of Recitations and several categories of related and un related phrases, we found that the best algorithm that can be used to improve the accuracy for the phrasal string is "Levenstein".

We have implemented this mechanism. The accuracy is very promising, and it can reach up to $100 \%$ in all of the tests that we carried out given that the settings and the rules stated before are respected.

\subsection{Voice-Driven Desktop Application Development}

A separate desktop application is developed employing the invented Speech Independent Recognition Engine. The application is interactive allowing the user to say the command, recognize it and then execute it. For example, the user first Says, "I want to listen to Recitation", then he/she pronounces the name of the recitation, ex 
"Idrees Alhadad An Khalaf”, then he/she pronounces the name of the Surat, ex, "Surat AlMaaidah", then he/she pronounces the number of the first and the last Verse, they user can also specify if the system should repeat the verses or wait between them. After that, the system recognizes all these commands and processes them. Then, it fetches the matching audio files and plays them back sequentially for the user.

The application has many features and is suitable for the real use by blind and handicapped people. We have prepared several videos showing how to use the application and its use in real time. You can access these videos from the system website at http://quranbyvoice.asites.org/demos.html.

\subsection{Accessing the Digital Library Contents Using API's}

The digital library that we have constructed is organized in a well-structured logical structure. We have developed several API's for controlling the access to its contents. These API's allows any user, any web site owner, or any application to access the contents of the library without the need for the developed application.

The contents of the digital library are currently hosted on web server and can be accessed using the HTTP protocol.

The base URI, BaseURI, is as follows:

BaseURI = http://quranbyvoice.asites.org/Player.html?doPlay=1\&PlayerType.

\subsubsection{Accessing the Recitations}

The API to access the recitations is as follows:

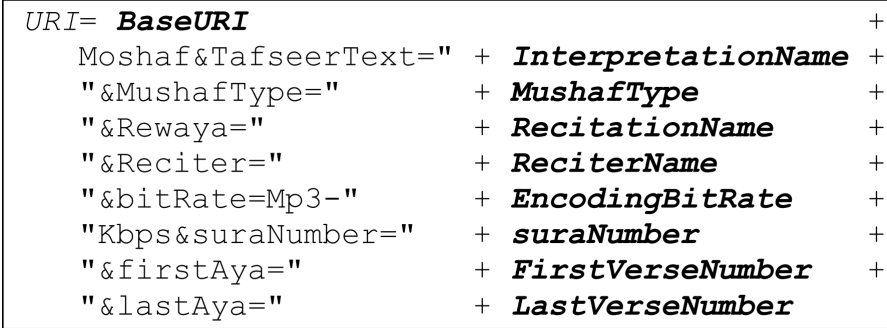

where InterpretaionName is given according to Table 1. This interpretation is textual and it will be displayed with Quran text on the screen. MushafType can be one of the following: $\{$ Hafs, Tajweed\}, where Hafs is for the Madina printed copy of the Quran, and Tajweed is another printed copy of the Quran colored according to the Tajweed rules. Recitation Name is given according to Table 2. EncodingBitRate can be one of the following: $\{8$, 32, 64, or 128\} Kbps. SuraNumber range from 1 to 144 according to the Index number of the Surah. FirstVerseNumber and LastVerseNumber are used to set the range for the verses the user wants to listen to.

For an interactive GUI for using that API, the user can visit the following link: http://quranbyvoice.asites.org/qiraat.html.

\subsubsection{Accessing the Mutoon}

The API to access the Mutoon is as follows.

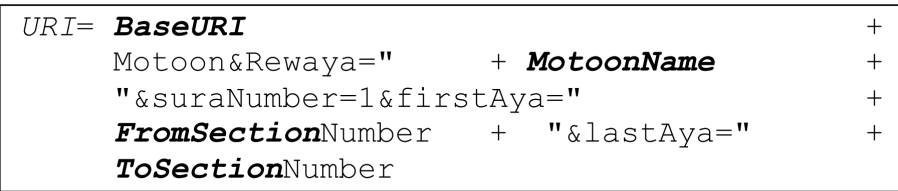

where MotoonName is given according to the following table. Each Matten is divided into several sections. Each Section is recorded in a separate audio file. Thus, FromSectionNumber and ToSectionNumber control the range of the Sections the user wants to listen to.

For an interactive GUI for using that API, the user can visit the following link: http://quranbyvoice.asites.org/motoon.html. 
4.3.3. Accessing the Tafseer (Interpretations)

The API to access the interpretations (Tafseer) is as follows

\begin{tabular}{|llrr|}
\hline URI= BaseURI & & & + \\
Moshaf\&TafseerText="+ & InterpretationName & + \\
"\&MushafType=" & + & MushafType & + \\
"\&Rewaya=" & + & AudioTafseerName & + \\
"\&PlayQuranWithTafseer=" & + PlayQuranWithTafseer & + \\
"\&suraNumber=" & + suraNumber & + \\
"\&firstAya=" & + FirstVerseNumber & + \\
"\&lastAya=" & + LastVerseNumber & \\
\hline
\end{tabular}

where the values of InterpretationName, MushafType, suraNumber, FirstVerseNumber and LastVerseNumber are given as described in Section 4.3.1). The value of AudioTafseerName can be currently Moyassar for the

Table 1. The Name of the interpretation and the value of the InterpretationName variable.

\begin{tabular}{cc}
\hline Name of the Interpretation & Value of InterpretationName \\
\hline Almoyassar Interpretation & Moyassar \\
Al-Saadi Interpretation & AlSaadi \\
Inb-Katheer Interpretation & IbnKatheer \\
Al-Jalalin Interpretation & AlJalalin \\
Al-Tabari Interpretation & Altabari \\
Al-qurtubi Interpretation & Alqurtobi \\
\hline
\end{tabular}

Table 2. The value of the recitation name for the given 20 recitations.

\begin{tabular}{cc}
\hline Recitation Name & Value of RecitationName \\
\hline Hafs from Asim & hafs \\
Shoba from Asim & shuba \\
Qaaloon from Nafi & qaloon \\
Warsh from Nafi & warsh \\
Aldoory from Abi Amr & aldori_abuamr \\
Alsossi from Abi Amr & alsosi \\
Aldury from & aldori_kasaee \\
Abu Alhareth from Alkisai & abo_alhareth \\
Hisham from Ibn Amer & hesham_amer \\
Ibn Zakwan from Ibn Amer & ibnthakwan \\
Khalaf from Hamza & khalaf_hamza \\
Khallad from Hamza & khallad \\
Ibn Werdan from Abu Ja'far & ibnwartan \\
Ibn Jammaz from Abu Ja'far & ibnjammaz \\
Rwis from Jacob & roways \\
Rooh from Jacob & rawh \\
Ishaq from Khalaf & eshaq_khalaf \\
Idris from Khalaf & edris_khalaf \\
Albzi from Ibn Kathir & albuzi \\
Konbul from Ibn Kathir & qunbolfor \\
\hline
\end{tabular}


Al-Moyassar interpretation.

For an interactive GUI for using that API, the user can visit the following link: http://quranbyvoice.asites.org/tafseer.html.

\subsubsection{Development of the Website (Web Application)}

A Web application has been developed offering the access to all the contents of our digital library (text, audio and image files).

Please take a look at the current system interface in the following pages. You can test the program on the following link: http://quranbyvoice.asites.org/. Please note that it does not work on mobile devices as MS Silverlight is used for the development of client-side Interface (Figure 2).

\section{Learning Quran and Its Sciences for Blind, Manual-Disabled and Illiterarte People}

We have developed an application that makes use of all previously explained components, namely: the voice recognition engine that is presented in Section 4.3, the digital library that is presented in Section 3, the Web API's that are presented in Section 4.4.

The application is developed using C sharp, MS Silverlight 5 and MS .Net framework 4.0. When the application is installed on the computer it runs in the background and auto-start when the system boot.

It checks if there is Internet connection or not, and vocally warns the user if no active Internet connection. The application is totally controlled by the voice commands, no use of the mouse or the keyboard. There is no GUI, the application runs as hidden as there is no need to display control commands (buttons, menus, etc.) for these targeted categories of users.

All the commands are prerecorded in audio files. In a sequential interactive process, when the system expect some actions from the user, it plays back the prerecorded audio file containing all the available commands asking the user to say any of these phrases. Then, the microphone is activated and the user says any command he want orally. The Speech Recognition Engine processes the pronounced phrase and recognizes the command. This process is repeated until the identifying all the requirements of the user to execute a specific task. The execution of the task is by fetching all the required prerecorded audio files from the digital library and plays them back on the user's computer sequentially in a specific order.

Let's describe all the actions and how to navigate into the system through the voice commands.

\subsection{Main Menu Items (Controlled only by Voice Commands)}

When the application starts, it directly starts playing back the available commands for the main menu by asking

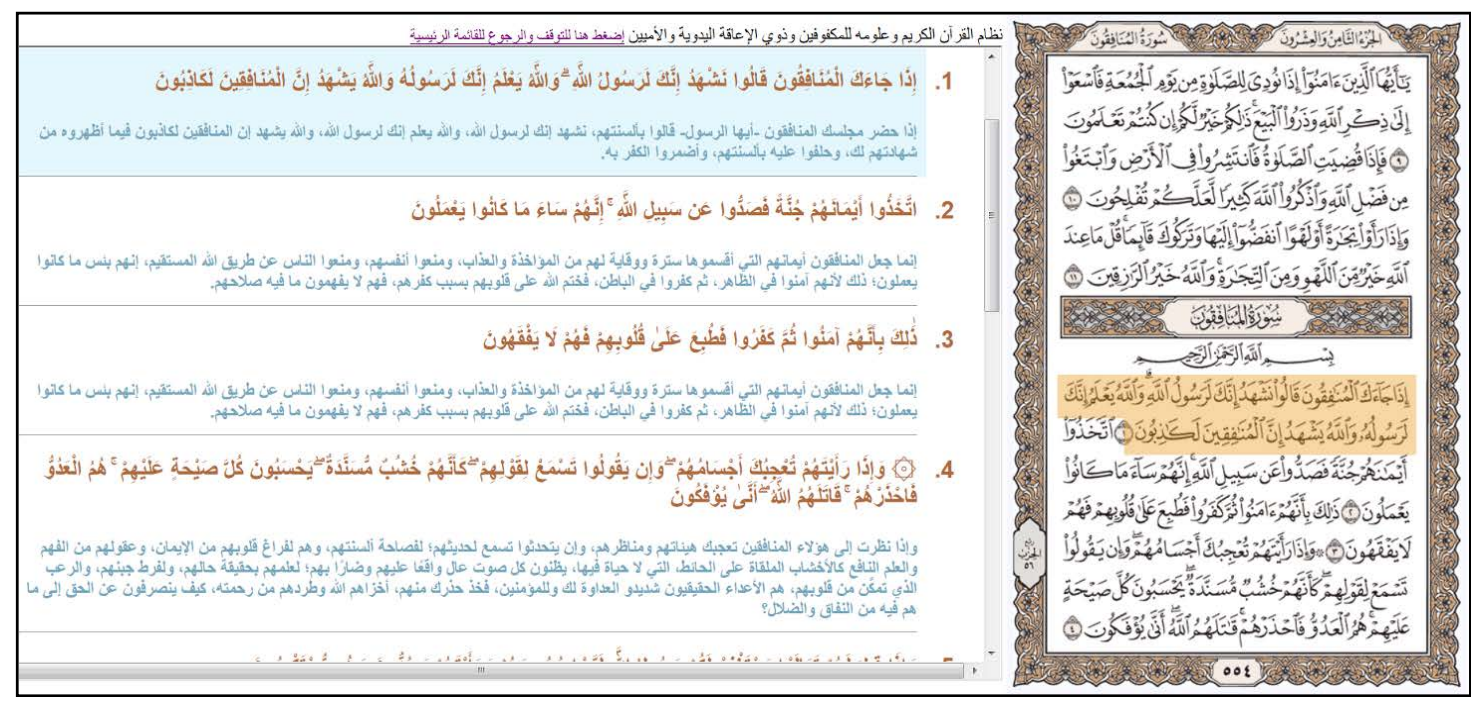

Figure 2. The user can listen to the Tafseer and the recitation of each verse. 
the user to pronounce one of the following phrases (in Arabic). These commands are:

1) Listen to Quran Recitation. See Section 5.2 for the rest of related interrogations to complete this action.

2) Listen to the interpretations of the Quran (Tafseer). See Section 5.3 for the rest of related interrogations to complete this action.

3) Listen to scientific Mutoon. See Section 5.4 for the rest of related interrogations to complete this action

4) Listen to Directions of use. Once the user pronounces this phrase, the system plays back a prerecorded user guide explaining how to use the system efficiently.

5) General Settings. Once the user pronounce this phrase, the system plays back another prerecorded message asking the user to select which option he/she wants to change in the behavior of the system.

6) The user then says any of the above phrases and the system recognizes the spoken commands and takes the appropriate action as described above.

\subsection{Recitation Menu Items}

When the user says "I want to listen to Quran recitation”, the system interrogates the user in a series of sub commands to know exactly what the user wants to hear.

First, the system asks the user to pronounce the name of the recitation. In the system, we have included all the 10 recitations and in each one there are two narrations. The user can say the name of any of these 20 narrations and the system recognizes which narration is required by the user.

Then, the system asks the user to pronounce the name of the Sura. The user then pronounces the name of any of the 114 Sura.

Then, the system asks the user to say the number of the starting verse.

Then, the system asks the user to say the number of the last verse he/she wants to listen to.

After that, the system asks the user to say if he/she wants to repeat the verse or not. This is very important to allow the users to memorize the verses (Quran Memorization).

If the user says that he/she wants to repeat the verses, then the system asks him/her to pronounce the number of repetitions.

The system then asks the user to specify if he/she wants to pause between the verse or not. If he says, "yes please pause between the verses", then the system waits the same time taken for playing back the previous verse. This is very important for people wants to memorize the Quran by repeating after the reciter.

Now, the system knows all the information required to execute the action. It downloads the audio files for the verses for the required Sura in the required recitation. Then the system starts playing them one by one.

\subsection{Interpretation (Tafseer) Menu Items}

When the user says "I want to listen to Quran interpretation”, the system interrogates the user in a series of sub commands to know exactly what the user wants to hear.

First, the system asks the user to pronounce the name of the interpretation. In the system, we have included two interpretations: Alsaadi and Almoyassar. The user can say the name of any of them.

Then, the system asks the user to pronounce the name of the Surat. The user then pronounces the name of any of the 114 Suras.

Then, the system asks the user to say the number of the starting verse.

Then, the system asks the user to say the number of the last verse he/she wants to listen to.

After that, the system asks the user to say if he/she wants to repeat the interpretation of the verse or not.

If the user says that he/she wants to repeat the interpretation of the verses, then the system asks him/her to pronounce the number of repetitions.

Now, the system knows all the information required to execute the action. It downloads the audio files for the interpretation of the verses for the required Sura in the required interpretation. Then the system starts playing them one by one.

\subsection{Scientific Material (Mutoon) Menu Items}

When the user says "I want to listen to Scientific Mutoon", the system interrogates the user in a series of sub commands to know exactly what the user wants to hear.

1) First, the system asks the user to pronounce the name of the scientific Matten (refer to Table 3. For the list 
Table 3. Value of the variable MotoonName according to the MattenName.

$\begin{array}{cc}\text { Name of the Matten } & \text { MotoonName } \\ \text { Matten Harz AlAmani Wa Wajh Attahani in seven readings (AlShatebya) } & \text { Shatebia } \\ \text { Matten AlDurra Almadhiyah in the three recitations } & \text { Aldorraa } \\ \text { Matten Almanzouma Aljazaria } & \text { Jazariea } \\ \text { Matten the masterpiece of children (Tuhfat Alatfal) } & \text { Tohfa } \\ \text { Matten Irjozat Aladab Fi Adab Altalab } & \text { Orjoozh } \\ \text { Matten Hediat Almurtab Fi Mutshabeh Alketab } & \text { Hedaya }\end{array}$

of the available scientific Mutoon). The user can say the name of any of them.

2) The user has three choices now: listening to the whole Matten, pronouncing the section title or by asking using the section number.

3) If the user choice to listen to the whole Matten, the system stop interrogating the user and start executing the action.

4) If the user says by "section title", the system asks the user to pronounce the section title and then stop interrogating the user and start executing the action.

5) Otherwise, the system asks the users to pronounce the number of the first section and the number of the last section.

Now, the system knows all the information required to execute the action. It downloads the audio files for the requested scientific Mutoon. Then the system starts playing them one by one.

\subsection{General Considerations}

In all cases, when the system asks the user to pronounce a specific phrase for an action, if the system fails to recognize the phrase or if the user does not pronounce the expected action correctly, the systems announce that the command could not be recognized and asks the user to try saying the command again.

\section{Conclusions and Future Directions}

In this Paper, we have presented a system that we have developed to help Blind, handicapped, illiterate, and the children who cannot use the mouse and the keyboard or who cannot read the text displayed on the screen to learn and benefit from the electronic materials for the Holy Quran and Its Sciences. Several applications were developed for them. These applications allows them to take a full control by dictating the commands orally and the system fetches the required materials in a format of prerecorded audio materials and plays them back to the users. We have developed a sophisticated Speaker Independent and Accent Independent Speech Recognition Engine based on Google Speech API. The achieved accuracy can reach up to $100 \%$ if a set of simple rules is followed during the dictation of voice commands.

We have prepared a huge digital library containing prerecorded audio files, text files and other materials for the Holy Quran Ten Recitations, the Twenty Holy Quran Narrations, the Five Major Quran Interpretations (Tafseer, namely: Ibn-Katheer, Alsaadi, Almoyassar, Al-Jallalin, Al-Tabari, and Al-Qurtobi) and the related Scientific Mutoon helping people to learn the Holy Quran and its Sciences.

We have developed a separate desktop application employing the invented Speech Independent Recognition Engine. The application is interactive allowing the user to say the command, the system then recognizes it and then it executes the commands. A web application and API's are developed allowing the users to interactively selecting any kind or portion of the prepared digital library to listen to.

Future research direction is how to generalize the idea for helping these people to learn. Example of that is how to make use of the system to allow the students to learn the courses interactively.

\section{Acknowledgements}

Dr. S. A. Elsagheer would like to thank Dr. Hisham H. Amin for the advices he provided to improve the accuracy of the speech recognition engine. 


\section{References}

[1] Mad Saad, S., Md Zain, M.Z., Hussein, M., Yaacob, M.S., Musa, A.R. and Abdullah, M.Y. (2010) A System Architecture of Electronic Braille Panel for Reciting Al-Quran. 2th International Conference on Computational Intelligence, Modelling and Simulation, Bali, 28-30 September 2010, 427-430. http://dx.doi.org/10.1109/CIMSiM.2010.56

[2] Abdallah, J., Abualkishik, M. and Omar, K. (2009) Quranic Braille System. International Journal of Humanities and Social Sciences, 3, 313-319.

[3] Abdul Khoni, N.A., Robason, A., Abdullah, Y., Musa, A.R., Md Zain, M.Z., Yaacob, M.S. and Hussein, M. (2010) A Novel Development of Electronic Braille. 2010 International Conference on Science and Social Research (CSSR 2010), 5-7 December 2010, Kuala Lumpur, 560-564.

[4] Mssraty, T. and Faryadi, Q. (2012) Teaching the Qur'anic Recitation with Harakatt: A Multimedia-Based Interactive Learning Method. International Journal of Scientific \& Engineering Research, 3.

[5] Abdo, M.S., Kandil, A.H., El-Bialy, A.M. and Fawzy, S.A. (2010) Automatic Detection for Some Common Pronunciation Mistakes Applied to Chosen Quran Sounds. 5th Cairo International Biomedical Engineering Conference, Cairo, 16-18 December 2010, 219-222.

[6] Abdou, S.M., Hamid, S.E., Rashwan, M., Samir, A., Abd-Elhamid, O., Shahin, M. and Nazih, W. (2006) Computer Aided Pronunciation Learning System Using Speech Recognition Techniques. Proceedings of International Conference on Speech and Language Processing, Pittsburgh, 17-21 September 2006, 849-852.

[7] Yekache, Y., Mekelleche, Y. and Kouninef, B. (2011) Towards Quranic Reader Controlled by Speech. International Journal of Advanced Computer Science and Applications, 2, 134-137. http://dx.doi.org/10.14569/IJACSA.2011.021123

[8] Ali, M., Elshafei, M., Al-Ghamdi, M., Al-Muhtaseb, H. and Al-Najjar, A. (2009) Generation of Arabic Phonetic Dictionaries for Speech Recognition. Journal of Information Technology Research, 2, 67-80.

[9] Razak, Z., Ibrahim, N.J., Idris, M.Y.I., Tamil, E.M., Yakub, M., Yusoff, Z.M. and Rahman, N.N.A. (2008) Quranic Verse Recitation Recognition Module for Support in j-QAF Learning: A Review. IJCSNS International Journal of Computer Science and Network Security, 8, 207-216.

[10] Carnegie Mellon University (2010) Sphinx—Speech Recognition Toolkit. http://cmusphinx.sourceforge.net/

[11] Lamere, P., Kwok, P., Gouvea, E.B., Raj, B., Singh, R., Walker, W. and Wolf, P. (2003) The CMU SPHINX-4 Speech Recognition System. Proceedings of the IEEE International Conference on Acoustics, Speech, and Signal Processing (ICASSP), 46, 37-51.

[12] Abushariah, M.A.M., Ainon, R.N., Zainuddin, R., Elshafei, M. and Khalifa, O.O. (2010) Natural Speaker-Independent Arabic Speech Recognitionsystem Based on Hidden Markov Models Using Sphinx Tools. 2010 International Conference on Computer and Communication Engineering, Kuala Lumpur, 11-12 May 2010, 1-6.

[13] Satori, H., Harti, M. and Chenfour, N. (2007) Introduction to Arabic Speech Recognition Using CMUSphinx System. Information and Communication Technologies International Symposium, Fes, 3-5 July 2007, 4 p.

[14] Hyassat, H. and Abu Zitar, R. (2008) Arabic Speech Recognition Using SPHINX Engine. International Journal of Speech Technology, 9, 133-150.

[15] Cambridge (2010) HTK—Hidden Markov Model Toolkit—Speech Recognition Toolkit. http://htk.eng.cam.ac.uk/

[16] Young, S., Evermann, G., Gales, M., Hain, T., Kershaw, D., Liu, X., Moore, G., Odell, J., Ollason, D., Povey, D., Valtchev, V. and Woodland, P. (1996) The HTK Book. Cambridge University Press, Cambridge.

[17] Tabbal, H., El-Falou, W. and Monla, B. (2006) Analysis and Implementation of a “Quranic” verses Delimitation System in Audio Files Using Speech Recognition Techniques. Proceeding of the IEEE Conference of 2nd Information and Communication Technologies, 2, 2979-2984.

[18] Ahmad, A.M., Ismail, S. and Samaon, D.F. (2004) Recurrent Neural Network with Backpropagation through Time for Speech Recognition. IEEE International Symposium on Communications \& Information Technology, 1, 98-102.

[19] Jurafsky, D. and Martin, J.H. (2007) Automatic Speech Recognition. Speech and Language Processing: An Introduction to Natural Language Processing, Computational Linguistics, and Speech Recognition. Prentice Hall, Upper Saddle River.

[20] IslamCity Website. http://www.islamicity.com/mosque/quran/

[21] IslamWay Website. The Most Famous Broadcast Website about Islam. http://en.islamway.net/

[22] Quran Readings. http://en.wikipedia.org/wiki/Qur\%27an_recitation 